\title{
Developing an outcomes-based charter to direct teaching and assessment of medical professionalism
}

\author{
R Delport, ${ }^{1} \mathrm{MSc}, \mathrm{MEd}, \mathrm{PhD} ;$ C Krüger, ${ }^{2} \mathrm{MB}$ BCh, MMed (Psych), MD, FCPsych (SA); M van Rooyen, ${ }^{3} \mathrm{MB}$ ChB, MMed (FamMed); \\ G Pickworth, ${ }^{4}$ DPhil (Psych)
}

${ }^{1}$ Skills Laboratory, Faculty of Health Sciences, University of Pretoria, South Africa

${ }^{2}$ Department of Psychiatry, School of Medicine, Faculty of Health Sciences, University of Pretoria, South Africa

${ }^{3}$ Department of Family Medicine, School of Medicine, Faculty of Health Sciences, University of Pretoria, South Africa

${ }^{4}$ Department for Education Innovation, University of Pretoria, South Africa

Corresponding author: R Delport (rhena.delport@up.ac.za)

Background. Components of professionalism in undergraduate medical studies at the University of Pretoria (UP) were previously defined as nine 'Golden Threads'. Although specific outcomes were formulated for the threads, the need for more explicit professional standards became increasingly evident. The restructuring of the health system in South Africa contributed to the need for more explicit standards. The Charter for Medical Professionalism was developed during 2006 - 2008 as a reference document within the local context to serve as a standard for professionalism in the medical curriculum. Another aim was to guide academics in medical studies to act as good role models of professional behaviour.

Objective. To document the development of the Charter for Medical Professionalism and to evaluate lecturer and student perceptions on the formulation of the Charter to make appropriate changes and increase acceptance.

Methods. The project took the form of action research, and a working group comprising academics from UP's Faculty of Health Sciences developed the Charter from relevant source documents, employing thematic and content analysis and recursive abstraction. An online survey was conducted to assess lecturer and student acceptance of the Charter.

Results. The outcomes-based approach was perceived as acceptable and appears to broaden the scope of assessment of professionalism.

Conclusion. Inclusion of outcomes proposed by other work groups relating to research, practice management, teaching, mentoring and leadership roles of the medical doctor may be considered in future.

Afr J Health Professions Educ 2015;7(1):10-15. DOI:10.7196/AJHPE.223

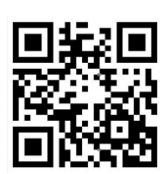

\section{Background}

The word 'professions', derived from the Latin professio, refers to a public declaration of a belief, a faith or an opinion and implies that members of professions will act in certain ways and strictly adhere to a well-defined code of conduct. ${ }^{[1]}$ Professionalism is an important aspect of any high-level occupation; for medical doctors it is an important component of their contract with society. ${ }^{[2]}$

There must be a clear definition of professionalism set out in a code of conduct and accepted by society, members of faculty of medical schools and their students. It should lend itself to change, as professionalism is dynamic, evolves and is multidimensional. ${ }^{[3]}$ It is important to ensure that medical graduates know their code of conduct and understand what is implied by 'professionalism' in a work-related context. This is especially important in South Africa (SA)'s rainbow nation', where a number of threats, including restructuring of the healthcare system, fiscal constraints and conflicts of interest, may erode medical professionalism.

The Physician's Charter for the new millennium ${ }^{[4]}$ is a representation of global opinion on the principles and commitments that pertain to medical professionalism. Desirable professional attributes for medical staff include being a reflective practitioner, responding to social needs, evincing core humanistic values, being accountable, and committing to scholarship and excellence. ${ }^{[5-7]}$ From an identified and agreed-on definition of 'professionalism', clear outcomes can be developed and its components become evident through corresponding behaviour. Strong support exists for professionalism to be considered as an explicit learning outcome, a skill set or a competency. ${ }^{[8-11]}$
The School of Medicine, University of Pretoria (UP), SA, has employed a number of strategies to promote professionalism, i.e. a University of Pretoria Pledge for Medical Students has been developed and since 1996 it has been customary for final-year medical students to make their pledge at a special ceremony. It is similar to the Declaration of Geneva (2006) but, in addition, students pledge to remain competent practitioners through lifelong learning. ${ }^{[12]}$

Furthermore, in the course of restructuring the undergraduate medical curriculum at UP (from 1997 onwards), a number of 'Golden Threads' were included in the curriculum, building progressively on what had been learnt in previous years. ${ }^{[13]}$ These Golden Threads embody important non-physical, humanitarian knowledge, attitudes and professional skills that medical students should have at the end of their 6-year course. Several of these threads - in particular those related to interpersonal skills, professional attitudes, teamwork and ethics - contributed to the development of what came to be called 'soft skills. ${ }^{\text {'14,15] }}$ The Soft Skills project explored and described undergraduate medical students' experiences of and viewpoints on soft skills and soft-skills development as part of their professional socialisation as doctors during the 6-year medical education programme. ${ }^{[14,15]}$ Students appeared to be more aware of their development of these soft skills within the new problem-orientated UP medical curriculum than students in the traditional curriculum. ${ }^{[14,15]}$

The concept of a local charter for professionalism developed in the course of formal and informal feedback during 2006 - 2007 from lecturers and medical students. It was clear that all professional standards needed to be defined more clearly within the medical curriculum. For example, 
from their assessment of medical students' assignments on professionalism over 5 years of study, Du Preez et al. ${ }^{[13]}$ concluded that such professional standards could be formulated in a charter that stated the principles and commitments relevant to UP and to which all medical professionals should aspire. Appropriate assessment of students' professionalism, defined by the outcomes in the Charter, would be of vital importance, as assessment reportedly drives learning. ${ }^{[16]}$ Assessment strategies purportedly not only raise awareness among students and faculty members of the core values of professionalism, but also demonstrate the importance of the development of these attributes to the institution. ${ }^{[5,6,17]}$ Therefore, continuous and diagnostic assessment would aid the early detection of unprofessional conduct and lead to timely remediation.

From a previous survey it became evident that the Charter should have a distinct local character, as the Physician's Charter was not perceived as totally acceptable within the SA context by $76 \%$ of fifth-year medical students at UP. ${ }^{[1]}$ A subsequent cohort of fifth-year students was required to define professionalism, and described features of professionalism that could possibly be assessed. ${ }^{[18]}$ A qualitative design was employed in this second study to explore students' perceptions. Attributes used to describe professionalism were grouped under four main domains: attitude and personal conduct; teamwork; patient care; and professional competence. Although similarities with the Physician's Charter were observed, most students expressed the opinion that the humanistic attributes of professional behaviour, such as empathy, good interpersonal relationships, integrity, respect, maturity and teamwork, were not obviously represented in the Physician's Charter. Van Rooyen and Treadwell[18] concluded that a locally acceptable charter should be developed for the School of Medicine, UP. It was envisaged that the Charter should reflect the essence of the existing Golden Threads, the guidelines set by the Health Professions Council of South Africa (HPCSA) for professional conduct (HPCSA Professional Guidelines ${ }^{[19]}$ and UP's Pledge for Medical Students. Although other bodies were also in the process of defining outcomes for professionalism, e.g. the Association of American Medical Colleges, ${ }^{[20]}$ UK General Medical Council $(\mathrm{GMC}){ }^{[21]}$ Scottish Deans Medical Curriculum Group ${ }^{[22]}$ and Royal College of Physicians and Surgeons of Canada, ${ }^{[23]}$ not all publications resulting from these international projects were consulted for the formulation of the charter within the UP context.

To summarise, the development of the UP Charter for Medical Professionalism was deemed necessary, as a need existed to explicitly define locally relevant standards of professionalism. Defining specific outcomes and assessment criteria relating to medical professionalism would lend consistency to the teaching and assessment of professionalism throughout the medical curriculum and aid in the early detection and remediation of unprofessional conduct. Furthermore, professional development of medical staff would result from their being informed about what was expected of a medical professionalism role model.

\section{Methods}

The development of the Charter was conducted as an action research project. Qualitative data were generated from the sources listed below, using thematic and content analysis and recursive abstraction. A representative working group was comprised from the School of Medicine, UP, and included a health sciences education advisor, family physician-lecturer, Department of Psychiatry lecturer, and the Procedural Skills Unit head. The project was conducted from November 2006 to November 2008.
The sources used for the development of the Charter were:

- The University of Pretoria Pledge for Medical Students

- The Golden Threads outcomes ${ }^{[13]}$

- The HPCSA Professional Guidelines ${ }^{[19]}$

- Medical professionalism in the new millennium: A Physician's Charter (participants in the Medical Professionalism Project 2002) ${ }^{[4]}$

- Good Medical Practice, GMC. ${ }^{[21]}$

All lecturers from the School of Medicine were invited via corporate email to participate in the study. A survey was conducted to source anonymous feedback on the Charter with the use of an online survey tool, Survey Monkey (http://www.surveymonkey.com). Following incorporation of comments from lecturers, students were invited to participate anonymously in the survey via a pop-up message and link on the university's learning management system. Respondents had to select one of the following options: agree/reject/reword for the competencies, values and attributes within the domains of professionalism, and for the descriptors of how the competencies may become evident.

Consensus was reached within the working group on whether the student comments were too poorly worded for consideration or inappropriate and which changes should be made to the Charter. The revised Charter was then presented to lecturers at undergraduate teaching committee meetings, strategic meetings of the School of Medicine, and induction programmes for newly appointed lecturers. No further proposals were made on invitation to improve the Charter, suggesting general acceptance by faculty.

Ethical approval for the study 'Teaching/learning, assessment and monitoring of medical students' professional conduct based on a Charter for professionalism' was granted by the Ethics Committee of the Faculty of Health Sciences (No. 63/2007). Consent was implied by anonymous participation.

\section{Results}

Complete responses were received from 52 lecturers in the School of Medicine, 6 of whom were full professors, 9 associate professors, 20 senior lecturers, and 17 lecturers. The student response rate was $15.3 \%$, after exclusion of incomprehensible, incomplete or obviously ridiculous responses. The number of respondents per year group 1 - 6 were 83,21, 42, 15, 6 and 17, respectively.

High levels of agreement in the selection and wording of items were observed in the responses of lecturers and students. The highest percentage for 'reject' (7.6\%) was observed to relate to the following professional competence: 'As a medical practitioner or student I am required to demonstrate knowledge and understanding of the principles of managed health care and health care systems in South Africa with special reference to the differences between the public and private sector. The highest percentage for rewording for any given item was $4.5 \%$. This competency was formulated as follows: 'As a medical practitioner or student I am required to demonstrate a relevant epidemiological approach. Table 1 presents all comments and suggestions made within the three domains of professionalism in relation to any of the listed requirements and how they become evident. Table 2 lists the two domains with three separate statements in which relevant comments were made that were suggestive of a poor correlation between the proposed professionalism outcomes and the reality of the workplace. Only $2 \%$ of respondents suggested that a descriptor of an outcome be reworded.

The revised Charter for Medical Professionalism is presented in Table 3, highlighting what lecturers and students regard as locally relevant standards for medical professionalism. 
Table 1. Specific feedback from student respondents about the three domains of professionalism

\begin{tabular}{lll}
\hline Domain & Original wording of item & Comment/suggested change \\
\hline Professional competence & $\begin{array}{l}\text { Problem-solving and critical thinking skills are evident } \\
\text { when I: } \\
\text { - Formulate a management plan after negotiation with } \\
\text { the patient/parent/guardian }\end{array}$ & $\begin{array}{l}\text { Problem-solving and critical thinking skills are evident } \\
\text { when I: } \\
\text { - Formulate a management plan before negotiation (to get an } \\
\text { idea of what you plan to do), but am able to adapt it after } \\
\text { discussion with patient/parent/guardian (once you have } \\
\text { received a better idea of the situation) }\end{array}$ \\
$\begin{array}{l}\text { Being knowledgeable of and applying relevant laws are } \\
\text { evident when I: }\end{array}$ & $\begin{array}{l}\text { Addition to the end of the statement: } \\
\text { - Remonstrate personal responsibility and ethical } \\
\text { behaviour in my conduct }\end{array}$ & $\begin{array}{l}\text { Realising that one cannot be taught to be ethical and } \\
\text { responsible in medical school but must do so in a personal } \\
\text { capacity first }\end{array}$ \\
$\begin{array}{l}\text { Demonstrate a commitment to improving my } \\
\text { knowledge and skills on a continuous basis }\end{array}$ & $\begin{array}{l}\text { Demonstrate a commitment to improving knowledge and } \\
\text { skills where possible }\end{array}$
\end{tabular}

Being knowledgeable of and understanding the principles of managed healthcare and healthcare systems in SA are evident when I:

- Apply the principles of managed healthcare, including the principles of fair distribution of healthcare resources, social justice, and access to healthcare for all

Ethical values

Ethical values require me to:

- Strive to ensure the well-being of all members of society

Acknowledging patient autonomy and empowering patients to make informed decisions are evident when I:

- Negotiate a treatment plan with patients

Acknowledging people's human rights is evident when I:

- Respect a patient's rights and needs

Acknowledging patient autonomy and empowering patients to make informed decisions are evident when I: - Respect their concerns and choices

Personal attributes

Upholding and maintaining professional behaviour and relationships are evident when I:

- Show maturity by a willingness to learn from others, accept constructive criticism, and acknowledge my errors and limitations
I feel that this decision is usually not made by the doctor - it is made by the management running the hospital, and lack of resources to adequately treat patients is a common complaint in many places. This is not usually because of a lack of money, but rather bad management

Ethical values require me to:

- Strive to ensure the well-being of all members of society who seek my professional assistance

Acknowledging patient autonomy and empowering patients to make informed decisions are evident when I:

- Negotiate a treatment plan with patients that best meets both myself, the patients' and their relatives' needs

Acknowledging people's human rights is evident when I:

- Respect a patient's rights and needs as required from me by law and unspoken guidelines

Unless their choices stand to harm others, especially in the cases of adults making decisions for children

I will accept criticism only if it is fully informed and takes availability of hospital resources into account

... but not stand for unfair and unjust treatment based on my level of education or my race

Table 2. Specific feedback from student respondents suggestive of discordance between the proposed professionalism outcomes and workplace reality

\begin{tabular}{|c|c|c|}
\hline Domain & Original wording of item & Comment/suggested change \\
\hline Professional competence & $\begin{array}{l}\text { Being knowledgeable of and understanding the principles of } \\
\text { managed healthcare and healthcare systems in South Africa are } \\
\text { evident when I: } \\
\text { - Apply the principles of managed healthcare, including the } \\
\text { principles of fair distribution of healthcare resources, social } \\
\text { justice, and access to healthcare for all }\end{array}$ & $\begin{array}{l}\text { I feel that this decision is usually not made by the doctor } \\
\text { - it is made by the management running the hospital, and } \\
\text { lack of resources to adequately treat patients is a common } \\
\text { complaint in many places. This is not usually because of a } \\
\text { lack of money - but, rather, bad management }\end{array}$ \\
\hline Personal attributes & $\begin{array}{l}\text { Upholding and maintaining professional behaviour and } \\
\text { professional relationships are evident when I: } \\
\text { - Show maturity by a willingness to learn from others, accept } \\
\text { constructive criticism, and acknowledge my errors and } \\
\text { limitations }\end{array}$ & $\begin{array}{l}\text { I will accept criticism only if it is fully informed criticism } \\
\text { and if it takes availability of hospital resources into } \\
\text { account } \\
\ldots \text { but not stand for unfair and unjust treatment based on } \\
\text { my level of education or my race }\end{array}$ \\
\hline
\end{tabular}




\section{Table 3. The Charter for Medical Professionalism: University of Pretoria}

- This charter guides the professional practice of medical students and practitioners. Both students and practitioners are required to commit themselves to: being informed of their professional responsibilities; a desire to maintain professional behaviour; and maintaining high standards of medical practice

- Students and practitioners should demonstrate (i) professional competence; (ii) adherence to ethical values; and (iii) the personal attributes that are associated with professionalism

- This charter shows what is expected of students and practitioners in terms of all three of these components of professionalism and also sets out how professionalism is made evident in conduct

\section{Professional competence}

As a medical practitioner or student I am required to:

- Demonstrate problem-solving and critical thinking skills

- Keep good clinical records

- Demonstrate a relevant epidemiological approach

- Be knowledgeable and apply relevant laws with special reference to:

- Human rights

- Relationships (collegial, patient and personal)

- Unlawful conduct

- Patient procedures (e.g. involuntary admission, etc.)

- Demonstrate knowledge and understanding of the principles of managed healthcare and healthcare systems in South Africa, with special reference to the differences between the public and private sectors

- Demonstrate a commitment to improving my knowledge and skills on a continuous basis

\section{Making these skills and qualities evident}

- Problem-solving and critical thinking skills are evident when I:

- Apply appropriate knowledge (anatomy, physiology, pathology, ethics, etc.) and skills (interpersonal, communication, physical skills, etc.) in the clinical assessment and treatment of patients

- Display an evidence-based approach while considering the availability of resources

- Formulate a management plan after negotiation with the patient/parent/guardian

- Accommodate in myself a degree of uncertainty in clinical decision-making and possible differences of opinion with others

- Keeping good clinical records is evident when I:

- Record information on the patient and matters relating to patient management in the appropriate format and regularly update this information

- Demonstrating a relevant epidemiological approach is evident when I:

- Determine the extent of the healthcare problem

- Plan and implement interventions using existing resources

- Apply appropriate methodology

- Being knowledgeable of and applying relevant laws are evident when I:

- Demonstrate knowledge of the South African Constitution and relevant laws in my clinical practice

- Demonstrate personal responsibility and ethical behaviour in my conduct

- Being knowledgeable of and understanding the principles of managed healthcare and healthcare systems in South Africa are evident when I:

- Apply the principles of managed healthcare, including the principles of fair distribution of healthcare resources, social justice, and access to healthcare for all

- A commitment to continually improving my knowledge and skills for the improvement of my professional competence is evident when I:

- Practise evidence-based medicine

- Inform my practice with up-to-date information and research

- Engage in continuing professional development

\section{Ethical values}

Ethical values require me to:

- Demonstrate an appropriate ethical approach to dilemmas in clinical practice and research

- Acknowledge people's human rights

- Acknowledge patient autonomy and empower patients to make informed decisions

- Uphold honesty as a primary concern

- Strive to ensure the well-being of all members of society 


\section{Table 3. (continued) The Charter for Medical Professionalism: University of Pretoria}

\section{Making these values evident}

- An appropriate ethical approach to clinical and research ethical dilemmas is evident when I:

- Identify ethical dilemmas in clinical practice and research

- Am accountable in my responses to these dilemmas

- Acknowledging people's human rights is evident when I:

- Respect a patient's rights and needs

- Treat people in a fair and just manner

- Acknowledging patient autonomy and empowering patients to make informed decisions are evident when I:

- Inform patients correctly of their treatment options

- Respect their concerns and choices

- Negotiate a treatment plan with patients

- Upholding honesty as a primary concern is evident when I:

- Demonstrate honesty in all my communications and dealings with patients and base all my dealings with patients on integrity

- Striving to ensure the well-being of all members of society is evident when I:

- Manage available resources responsibly

\section{Personal attributes}

The personal attributes of a medical student or doctor require me to:

- Uphold and maintain professional behaviour and professional relationships

Making these attributes evident

- Upholding and maintaining professional behaviour and professional relationships are evident when I:

- Demonstrate desirable personal attributes (such as compassion, empathy, honesty, tolerance, integrity, responsibility, trustworthiness, confidentiality, beneficence, respect for the primacy of the patient, transparency in decisions) in my relationships with patients

- Show respect in my demeanour, grooming, adherence to the appropriate dress code, punctuality and attendance

- Show maturity by a willingness to learn from others, accept constructive criticism, and acknowledge my errors and limitations

- Am able to handle conflict and make appropriate decisions and cope in a crisis

- Have good communication and interpersonal skills, such as knowing how to greet patients appropriately and listening well

- Show the ability to work in a team through delegating and making referrals appropriately, sharing with colleagues, valuing the input of all team members and recognising all contributions of the team.

\section{Discussion}

The Charter for Professionalism of the School of Medicine, UP, was developed to promote a common understanding of how professionalism may become evident, thus heightening student (and lecturer) awareness of professionalism and assuring consistency in the teaching and assessment of professionalism in medicine.

To assure 'buy-in' from the School of Medicine, the Charter was specifically developed to accommodate the previously defined Golden Threads. Other sources - as listed under Methods - were included in the research process, and feedback from faculty and students was sourced in a local survey. Generally, the survey responses supported the current form of the UP Charter. Although the response rate of the students was relatively low, all years of study were represented. Students are continually invited to comment on the Charter as part of their reflection activities.

Comments made by students mostly provided evidence of buy-in, as they proposed subtle changes to the wording of specific outcomes. Some of the comments, however, indicated that discordance might exist between the proposed professionalism outcomes and workplace reality, where resources to treat patients adequately are often lacking (Table 1). The assessment of professionalism within the macro-societal domain may become complicated as a result of a dysfunctional system that needs to be accounted for. As proposed in the Assessment of professionalism: Recommendations from the Ottawa 2010 Conference,, ${ }^{[24]}$ future research may be directed towards exploring 'professionalism assessment in complex clinical workplaces, including how individuals adapt to difficult or even dysfunctional health care systems and the gaps that arise between espoused values and actual practice'.

The hallmark paper 'Health professionals for a new century: Transforming education to strengthen health systems in an interdependent world' proposes that a competencies-based approach within team-based learning be employed and that global learning should be strengthened. ${ }^{[25]}$ The outcomes-based approach of the UP Charter is therefore in agreement with international trends, as it defines measurable or observable competencies, albeit within the SA context. Cross-referencing between outcome frameworks is, however, indicated. ${ }^{[26]}$ Such an endeavour would aid in identifying gaps and promoting a common understanding of professionalism in the workplace, as is evident from the attributes or competencies proposed for the 'global doctor' (The Tuning Project (Medicine), 2012). ${ }^{[27]}$ The unique nature of professionalism as described and understood locally within different medical schools and healthcare disciplines should, however, be appreciated and maintained.

Agreement between the outcomes defined in UP's Charter for Medical Professionalism and those defined in The Tuning Project, ${ }^{[27]}$ Tomorrow's Doctors, ${ }^{[28]}$ The Scottish Doctor ${ }^{[29]}$ and The American Board of Internal Medicine (ABIM) Foundation, ${ }^{[30]}$ is highly evident. What appears to be lacking in the UP Charter, however, is emphasis on research, practice management, and teaching, mentoring and leadership roles of the doctor. Furthermore, identification of the attributes of the global doctor is 
commendable and merits contextualisation and inclusion in the UP Charter. In general, the outcomes-based approach appears to broaden the scope of assessment of professionalism beyond observing behavioural attributes.

The Charter is regarded as a working document and is intended to serve as a basis for local discourse on professionalism within a global and transdisciplinary context in health sciences.

\section{Conclusion}

Defining outcomes for professionalism in medical practice appears to be universally acceptable. This approach evidently makes professionalism more explicit and assessable and also broadens the scope of professionalism by virtue of defining new roles and responsibilities within the individual, interpersonal, and societal/institutional domains.

Acknowledgements. The authors would like to acknowledge the valuable contributions of former members of the Charter for Medical Professionalism Work Group: Ina Treadwell, Renata du Preez and Isobel van der Westhuizen.

\section{References}

1. Merriam-Webster.com 2012. http://www.merriam-webster.com/dictionary/professions (accessed 18 December 2012). 2. Cruess RL, Cruess SR. Expectations and obligations: Professionalism and medicine's social contract with society Perspect Biol Med 2008;51(4):579-598.

3. Hafferty FW, Castellani B. The increasing complexities of professionalism. Acad Med 2010; 85:288-301. [http:// dx.doi.org/10.1097/ACM.0b013e3181c85b43]

4. Members of the Medical Professionalism Project: ABIM Foundation, ACPBASIM Foundation, and European Federation of Internal Medicine. Medical professionalism in the new millennium: A physician's charter. Lancet 2002;359:520-522. [http://dx.doi.org/10.1016/S0140-6736(02)07684-5]

5. Schuwirth L. Professional development in undergraduate medical curricula from an assessment point of view Med Educ 2002;36(4):312-313.

6. Ten Cate ThJ, De Haes JCJMM. Summative assessment of medical students in the affective domain. Med Teach 2000;22(1):40-43. [http://dx.doi:10.1080/01421590078805]

7. Swick HM. Toward a normative definition of medical professionalism. Acad Med 2000;75:612-616. [http:// 7. Swick HM. Toward a normative definition of
dx.doi.org/10.1097/00001888-200006000-00010]

8. Frank JR, Danoff D. The CanMEDS initiative: Implementing an outcomes-based framework of physician competencies. Med Teach 2007;29:642-647. [http://dx.doi.org/10.1080/01421590701746983]
9. Harris P, Snell L, Talbot M, Harden RM. Competency-based medical education: Implications for undergraduate programs. Med Teach 2010;32:646-650. [http://dx.doi.org/10.3109/0142159X.2010.500703]

10. Van Mook WNKA, van Luijk SJ, O'Sullivan $\mathrm{H}$, et al. The concepts of professionalism and professional behaviour Conflicts in both definition and learning outcomes. Eur J Int Med 2009;20:e85-e89. [http://dx.doi.org/10.1016/j. ejim.2008.10.006

1. Van Rooyen M. The view of medical students on professionalism in South Africa. SA Family Practice 2004;46(1):28-31.

12. World Medical Association. WMA Declaration of Geneva. Geneva: World Medical Association, 2006. http:/ www.wma.net/en/30publications/10policies/g1/index.html (accessed 18 December 2012).

13. Du Preez RR, Pickworth GE, Van Rooyen M. Teaching professionalism: A South African perspective. Med Teach 2007;29:e284-e291

14. Joubert PM, Krüger C, Bergh A-M, et al. Medical students on the value of role models for developing 'soft skills' - 'That's the way you do it'. South African Psychiatry Review 2006;9:28-32. [http://repository.up.ac.za/ handle/2263/15029]

15. Bergh A-M, Van Staden CW, Joubert PM, et al. Medical students' perceptions of their development of 'soft skills' - Part II: The development of 'soft skills' through 'guiding and growing'. SA Family Practice 2006;48(8):15-15d [http://repository.up.ac.za/handle/2263/15024]

16. Epstein RM. Assessment in medical education. N Engl J Med 2007;356(4):387-396.

17. Papadakis MA, Loeser H, Healy K. Early detection and evaluation of professionalism. Deficiencies in medica students: One school's approach. Acad Med 2001;76(11):1100-1106.

18. Van Rooyen M, Treadwell I. Pretoria medical students' perspectives on the assessable attributes of professionalism. SA Family Practice 2007;49(4):17.

19. The Health Professions Council of South Africa. Professional Guidelines. http://www0.sun.ac.za/ruralhealth/ ukwandahome/rudasaresources2009/More/ProfessionalGuidelines.pdf (accessed 18 December 2012).

20. Association of American Medical Colleges. Learning objectives for medical student education: Guidelines for medical schools, 1998. http://www.aamc.org/meded/msop/ (accessed 18 December 2012).

21. The UK General Medical Council. Good Medical Practice. http://www.gmc-uk.org/guidance/good_medical_ practice.asp (accessed 18 December 2012).

22. The Scottish Deans Medical Curriculum Group. http://www.scottishdoctor.org/ (accessed 18 December 2012).

23. The Royal College of Physicians and Surgeons of Canada. CANMEDS Competency Framework 2005. http:// www.royalcollege.ca/portal/page/portal/rc/common/documents/canmeds/framework/the_7_canmeds_roles_e. www.royalcollege.ca/portal/page/port

24. Hodges BD, Ginsburg S, Cruess R, et al. Assessment of professionalism: Recommendations from the Ottawa 2010 Conference. Med Teach 2011;33(5):354-363. [http://dx.doi.org/10.3109/0142159X.2010.500703]

25. Frenk J, Chen L, Bhutta ZA, et al. Health professionals for a new century: Transforming education to strengthe health systems in an interdependent world. Lancet 2010;376(9756):1923-1958. [http://dx.doi.org/10.1016/S01406736(10)61854-5]

6. Ellaway R, Evans P, McKillop J, et al. Cross-referencing the Scottish doctor and tomorrow's doctors learnin outcome frameworks. Med Teach 2007;29(7):630-635. [http://dx.doi.org/10.1080/01421590701316548]

27. The Tuning Project (Medicine) 2012. Learning outcomes/competences for undergraduate medical education in Europe. http://www.tuning-medicine.com/exec.asp (accessed 18 December 2012).

28. UK General Medical Council. Tomorrow's Doctors 2009: A draft for consultation. https://gmc.e-consultation. net/econsult/uploads/TD\%20Final.pdf (accessed 18 December 2012).

29. The Scottish Doctor, 2011. Learning outcomes for attitudes, ethical understanding and legal responsibilities. http://www.scottishdoctor.org/node3.asp?id=0900000000 (accessed 18 December 2012).

30. The American Board of Internal Medicine (ABIM) Foundation. http://www.abimfoundation.org/Professionalism/ Physician-Charter.aspxian-Charter.aspx (accessed 18 December 2012). 